\title{
Integrated Development of Exhibition and Logistics Under Service Innovation Mode
}

\author{
Haiqin Fan $^{1}$ \\ ${ }^{1}$ Guizhou Minzu University, Guiyang, China
}

\begin{abstract}
Both exhibition and logistics belong to modern service industry, and they promote each other. However, the logistics industry has not received special attention and development in the field of exhibition at this stage, and the theoretical research is still in its infancy. After analyzing the characteristics of exhibition logistics deeply, this paper argues an integrated development mode of exhibition logistics under the service innovative mode, so as to improve the development of exhibition and logistics.
\end{abstract}

\section{Introduction}

Logistics refers to the process of goods physical flow, which including necessary links such as transportation, storage, loading and unloading, and expansibility links such as circulation processing, packaging [1]. Since the theory of logistics was introduced into China in the 1980s, it has been developing rapidly in China. Ant the same time, the theory and practice of logistics have been greatly enriched in China. With the support of the theory, it has enriched the logistics practice and promoted the rapid improvement of the logistics industry economy.

Exhibition includes conference and exhibition, which is characterized by strong relevance to other industries and strong driving force to regional economy [2]. Since the reform and opening up, China's Convention and exhibition industry has been developing unprecedentedly. Meanwhile, the exhibition industry belt in Northeast China centered on Dalian and Changchun, and the exhibition industrial belt in central and Western China centered on Xi'an and Chengdu are forming [3].

Both exhibition and logistics belong to the service industry, and they have been received corresponding support from the China's government. We can see from the relevant documents of international and local governments that the government has given a lot of policy support to the development of service industry, including exhibition and logistics. Each develops very well. However, the industry about the integration of exhibition and logistics has not received more attention from searchers and Industry specialty. From the perspective of service innovation mode, this paper analyzes the significance and means of the integrated development of exhibition and logistics industry.

\section{Overview of related research}

\subsection{Research on Service Innovation}

The early research about service innovation is mainly product-centered, emphasizing that technology is the key, and focusing on technology driven service innovation [4]. In the last century, the research about service innovation began to emphasize its own unique attributes, the application of manufacturing innovation methods in service industry, and revealed the essence of innovation activities [5]. In this century, the understanding of service innovation is developing in a multi-dimensional direction. Service innovation not only promotes the development of enterprises, but also is the competitive advantage of enterprises and the driving force of economic growth [6]. Generally speaking, the exploration of service innovation theory and practice is deepening.

\subsection{Overview of Research on Exhibition logistics}

The research on exhibition logistics is still in its infancy. At present, the research on exhibition logistics mainly starts from the following aspects:

- Supplier selection Perspective. According to the characteristics of exhibition logistics and basing on the basic principle of QFD (Quality Function Deployment), one method is that the evaluation index system of exhibition logistics service suppliers is constructed to facilitate the selection of exhibition logistics service suppliers [7]. The other method is based on the fuzzy comprehensive evaluation to evaluate, select and determine the logistics service providers [8].

- The perspective of the whole industry. After analyzing the similarities and differences between traditional enterprise logistics system and 
Convention and exhibition logistics system, the construction of modern exhibition logistics network is put forward. Then people analyze the construction of trade exhibition logistics system from the perspective of industrial cluster, so as to promote the upgrading of regional industrial clusters [9]. A new ecological system of trade circulation is built from the relationship between trade circulation and exhibition economy.

- The perspective of exhibition logistics management. The particularity of exhibition logistics itself makes a lot of benefit reversal phenomenon in exhibition logistics activities. To resolve this problem, the method of system integration is introduced to analyze the three stages of exhibition logistics management from function collection, supply chain management to logistics service provider alliance, so as to realize the integrated management of exhibition logistics [10].

With the rapid development of e-commerce in China, logistics technology, logistics informatization and logistics practice methods have been improved rapidly. Logistics has shown its own advantages in commodity circulation. However, the application of logistics in the field of exhibition industry has not been paid more attention. In the process of many exhibition planning, logistics service is not included in the planning scheme. The organizers of the exhibition did not regard logistics service as a part of the exhibition. They believe that the logistics activity of exhibits was decided by the exhibitors themselves

\section{Characteristics of exhibition logistics}

Compared with the general commodity circulation mode, exhibition logistics has its own particularity.

\subsection{Exhibition Logistics Belongs to Project Logistics}

The production and circulation of ordinary commodities have the characteristics of continuity. While, when the exhibition is regarded as a special commodity, its major function is to complete the commodity display at the specific time and specific place. Each exhibition logistics is arranged according to the needs of a specific exhibition. When the exhibition is over, the exhibition as a kind of commodity employment has no commodity characteristics. So, the exhibition has the characteristics of temporary and one-off projects, and the logistics providing services for the exhibition belongs to the project logistics, distinguished from the general logistics which working normally.

\subsection{The Complexity of Exhibition Logistics Process}

During the exhibition period, there are many participants such as exhibition organizers, exhibitors, visitors, media reporters, contribute to hold an exhibition successfully, so the process of the exhibition is a complex system engineering. After the time of the exhibition is determined, the logistics service provider needs to collect the relevant information of all the exhibitors and formulate the logistics plan and scheme. The exhibition has strict requirements on the time and quality of exhibits, which increases the difficulty of logistics transportation, storage and packaging, especially for special commodities, such as important cultural relics, fresh food, precision instruments. When it comes to international exhibitions, the time of customs declaration, customs clearance and inspection and quarantine should be considered to avoid the failure of timely exhibition and the exhibition of commodities with quality problems, which will affect the exhibition effect.

\subsection{The Contradiction Between Supply and Demand is Prominent}

Any exhibition project has the characteristics of specific exhibition time, fixed exhibition location, large number and wide distribution of participating enterprises, small amount of exhibits but many samples, which makes it difficult for exhibition logistics companies to realize the reasonable transportation of exhibits for participating enterprises, so as to safely transport the exhibits to the exhibition area at the lowest cost within the specified time.

Some large-scale exhibitions, such as China Import Expo, have cooperated with logistics service providers to solve the international and domestic transportation, packaging, storage and other logistics activities of exhibits But for many smaller-scale exhibitions, they have not formed strategic partnership with logistics service providers, and many logistics enterprises have not carried out exhibition logistics service projects.

Therefore, in the trend of vigorous development of the exhibition, there is a big contradiction between the supply and demand of logistics services.

\subsection{Strong Timeliness in Logistice Process}

Generally speaking, except for special circumstances, such as major natural disasters and events, the established exhibition time will not be postponed or rescheduled Therefore, strict requirements are put forward for the logistics management of the exhibition. In terms of exhibits distribution, logistics service providers should ensure that the exhibits can be transported to the exhibition site quickly, accurately and safely. If the exhibits are delivered too early, they will pay extra storage fees while the delivery is too late, the exhibition opportunity will be missed.

\subsection{Hghly specialized in Exhibition Logistics}

The characteristics of the exhibition industry determine that its organization and management work must have a higher level of specialization in order to highlight the personality and ensure the quality, especially in the aspect of exhibition logistics, the requirements for specialization are higher more than general logistics. In order to organize 
a exhibition well, we must have talents with professional skills in logistics management, smooth logistics channels, effective means of material distribution and complete material transfer and storage center as support. Therefore, the relatively high degree of specialization is a very significant feature of the exhibition logistics system.

\section{Integrated development mode of exhibition and logistics based on Service Innovation}

\subsection{The Relationship Between Exhibition Industry and Logistics Industry}

Exhibition industry and logistics industry belong to service industry. On the one hand, the research and application of exhibition in the field of logistics broaden the scope of research and practice of logistics industry. On the other hand, the effective application of logistics in the exhibition industry improve the service ability and service quality of the exhibition, thus increasing the satisfaction of exhibitors and visitors. The relationship between logistics and exhibition is mutual promotion and mutual influence.

\subsection{Operation Mode of Traditional Exhibition Logistics}

The organizer of the exhibition is only responsible for the organization, planning and actual operation of the exhibition. For exhibitors, how to show their products and services on the exhibition site, attract more visitors and find customers is the primary task of taking part in the exhibition. However, in the process of participating an exhibition, how to find logistics service providers to complete the transportation, packaging, loading and unloading and other logistics activities is often a thorny problem for the exhibitors. Sometimes the services what the unprofessional logistics service provide will affect the exhibition effect of the exhibitors.

Under the traditional exhibition mode, exhibition and logistics are independent, as shown in Figure 1. Under this mode, each exhibitor looks for the logistics service supplier by himself. For the exhibitors, it is necessary to pay the cost to find logistics service providers, and the exhibition products of individual exhibitors can't meet the scale required by logistics service suppliers, so the cost of logistics is high. For the same exhibition, different logistics service providers have different service capabilities. And the same time, cross operation of different logistics service providers on the exhibition site is an important obstacle for the implementation of the exhibition.

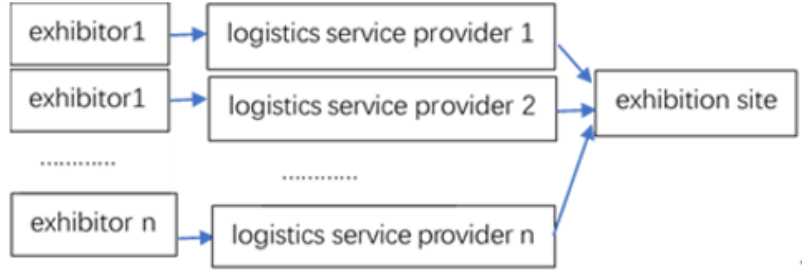

Fig1. Traditional exhibition logistics mode.

\subsection{Operation Process of Exhibition Logistics Under Service Innovation Mode}

In the exhibition logistics service, service innovation includes technological innovation, concept innovation and operation mode innovation. Technological innovation requires exhibition organizers and logistics service providers to use advanced technical means to improve service efficiency; concept innovation requires exhibition organizers to focus on the whole process before, during and after the exhibition, and pay attention to all aspects of promoting the quality of exhibition; and the innovation of operation mode requires improving process and increasing customer satisfaction from the perspective of customer experience.

Resorting to the innovative service mode, logistics service providers are the bridge which connect all parties participating in the exhibition, as shown in Figure 2.

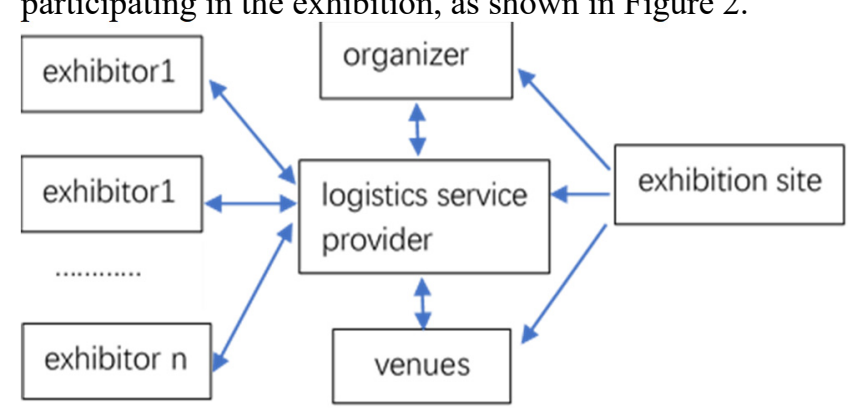

Fig2. Exhibition logistics mode under service innovation mode.

After the comprehensive evaluation of logistics service providers by the exhibition organizers, the logistics service providers who meeting the needs of the exhibition are selected and designated as the logistics service suppliers of the exhibition. The exhibitors inform the logistics service providers of their exhibition information, and then the logistics service providers will make overall arrangements and formulate corresponding logistics service plans. The logistics service scheme includes the forward logistics from the exhibitor to the exhibition hall, the reverse logistics from the exhibition hall to the exhibitor, and the logistics service after the visitors purchase products on site.

\subsection{The Process of Exhibition Reverse Logistics Under Service Innovation Mode}

Reverse logistics refers to the process of planning, implementing and controlling raw materials, semifinished products inventory, finished products and related information from the consumption point to the starting point in an efficient and cost-effective way, so as to achieve the purpose of recycling value and proper disposal. 
In the actual process of the exhibition, there are some differences between reverse logistics and traditional reverse logistics. The process of reverse logistics is shown in Figure 3.

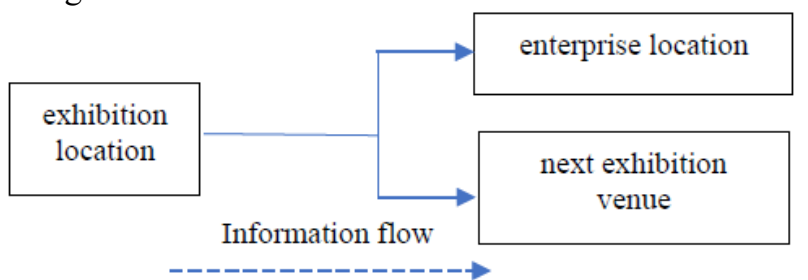

Fig3. Exhibition logistics mode under service innovation mode.

From a worldwide perspective, whether it is an international exhibition or a domestic exhibition, there are two possibilities for an exhibitor to attend an exhibition in a certain country or region: the country or region is its final destination and will return to the original place after the exhibition; the other is that the country or region is only one of its destinations, and his next trip is to attend the exhibition in a third country or region. If the exhibitors only participate in this exhibition, the exhibition reverse logistics is the process from the exhibition site back to the enterprise location. If the exhibitors want to continue to participate in the next exhibition, reverse logistics includes the whole process of return transportation.

No matter which form it is, reverse logistics is an indispensable link in the exhibition, and the reverse logistics, which also involves the transportation, packaging, loading and unloading of products, if it is an international exhibition, it also includes the customs declaration of exhibits, as complexity as to the forward logistics.

Under the innovative service mode, the exhibition organizers should provide more comprehensive, convenient and personalized services for exhibitors and visitors from the perspective of customers, so as to improve the satisfaction of exhibitors and visitors, so that the exhibition can continue to be held for many years and finally enhance the level and influence of the exhibition

\section{Conclusion}

Under the guidance and support of the state for the service industry, the integrated development of the exhibition industry and the logistics industry is an important means to improve the exhibition service quality, and is also an important way for the logistics industry to expand the practice field. This paper mainly analyzes the characteristics of exhibition logistics, then put forward the exhibition logistics mode under service innovation mode.

\section{References}

1. SONG Bo-huia, XU Shou-bob. "Discussion on Wuliu Definition". Journal of Beijing Jiaotong University(Social Sciences Edition).vol.9. pp.26-29, March 2010.

2. REN Li-jun. The Research on Convention \& Exhibition Economy. COMMERCI ALRESEARCH. vol.43. pp.50-53, January 2008.
3. ZHANG Wei. The Present Situation and Prospect of China's Exhibition Industry-Speech at the 73rd UFI

Annual Meeting [J]. China Exhibition, pp.49-55, October 2006.

4. Barras, R. Towards a theory of innovation in services[J]. Research Policy,vol 15, pp. 161 173,Augst 1986.

5. Gallouj. F. Innovation in services and the attendant old and new myths $[\mathrm{J}]$. The Journal of SocioEconomics, vol 31, pp, 137-154, March 2002.

6. Vargo, S and Lusch, R. Service-dominant logic: continuing the evolution[J] . Journal of the Academy of Marketing Science, vol 36, pp, 1-10, January 2008.

7. Cai Yiping, Peng Zhengguang, Zhang Mengfang. Study on Logistics Selection for Comprehensive Convention and Exhibition. Shanghai Management Science. Vol, 33, pp,48-50, June 2011

8. QIN Li-gong, JIANG Jun-mei, YUAN Yuan, JIANG Jun-bo. Choice of Modern Exhibition Logistics Provider Based on Fuzzy Comprehensive Evaluation. Journal of Guilin University of Technology. Vol, 32, pp,613-617, Apil 2012.

9. Baishang Zhang, Haitao Zheng, and Moqin Zhang. Research on the construction of trade exhibition logistics system of Industrial Cluster -- a case study of Guangdong Province. Industrial Technology Economy. vol, 26, pp,90-93, July 2007.

10. Zhihong Luo. Exhibition Logistics: Supply Chain System and Integrated Management Mode. Modern Logistics. vol,48, pp, 68-69, March 2009. 